\title{
Refractory Mycosis Fungoides
}

National Cancer Institute

\section{Source}

National Cancer Institute. Refractory Mycosis Fungoides. NCI Thesaurus. Code C8687.

Mycosis fungoides resistant to treatment. 